Revue de l'Institut des langues et cultures

d'Europe, Amérique, Afrique, Asie et Australie

26 | 2016

Mémoire, vérité et justice en Uruguay

\title{
Familia, violencia, memoria: D.F. de Mateo Gutiérrez (2008)
}

Famille, violence, mémoire : D.F. de Mateo Gutierrez (2008)

Family, Violence, Memory: D.F., Mateo Gutierrez (2008)

\section{Elizabeth Rivero}

\section{(2) OpenEdition}

\section{Journals}

Edición electrónica

URL: http://journals.openedition.org/ilcea/3980

DOI: $10.4000 /$ ilcea.3980

ISSN: 2101-0609

Editor

UGA Éditions/Université Grenoble Alpes

Edición impresa

ISBN: 978-2-84310-334-6

ISSN: $1639-6073$

\section{Referencia electrónica}

Elizabeth Rivero, «Familia, violencia, memoria: D.F. de Mateo Gutiérrez (2008) », ILCEA [En línea]

26 | 2016, Publicado el 07 julio 2016, consultado el 01 mayo 2019. URL : http://

journals.openedition.org/ilcea/3980 ; DOI : 10.4000/ilcea.3980

Este documento fue generado automáticamente el 1 mayo 2019.

(c) ILCEA 


\title{
Familia, violencia, memoria: D.F. de Mateo Gutiérrez (2008) ${ }^{1}$
}

\author{
Famille, violence, mémoire : D.F. de Mateo Gutierrez (2008) \\ Family, Violence, Memory: D.F., Mateo Gutierrez (2008)
}

\section{Elizabeth Rivero}

1 En sus apreciaciones acerca de la memoria cultural, Astrid Erll afirma que ésta no podría concebirse sin la existencia de los medios de comunicación ya que, tanto a nivel individual como colectivo, la mediación cumple una función primordial en la elaboración y trasmisión de memorias (Erll, 2011: 113). Para resaltar el puesto destacado que ocupa la cultura visual entre los diferentes medios de comunicación, especialmente la fotografía y el film, Erll recupera las palabras de Walter Benjamin quien, en su proyecto de los Pasajes sostenía que la historia se decanta en imágenes, no en palabras (Erll, 2011: 134). En el caso particular de los países del Cono Sur, tal como lo hiciera el Nuevo Cine Latinoamericano de la época de los sesenta, con posterioridad al advenimiento de la democracia en la década de los ochenta, el cine documental desempeña un rol social y político significativo, esta vez a la hora de recuperar y recrear la memoria doliente del pasado dictatorial. Dentro de estas producciones pos-dictatoriales destaca una serie de trabajos elaborados por hijos de quienes fueran víctimas de la represión y la violencia política los cuales, desde una perspectiva de carácter intimista y personal, intentan recuperar la figura de sus padres a través de las memorias fragmentarias de familiares y allegados, fotografías y antiguas filmaciones. Documentales como Los rubios de la argentina Albertina Carri (Argentina-Estados Unidos, 2003) y Mi vida con Carlos del chileno Germán Berger (ChileEspaña, 2010) son emblemáticos de estos esfuerzos y han recibido cierta atención de la crítica. Dentro de esta categoría se ubicarían también los documentales Papá Iván de María Inés Roqué (Argentina-México, 2004), Encontrando a Víctor de Natalia Bruschtein (México, 2005) y $M$ de Nicolás Prividera (Argentina, 2007), todos ellos sobre padres victimados por la dictadura militar argentina.

2 Menos conocidas son quizás este tipo de producciones en Uruguay y, por esta razón, en mi ensayo me propongo analizar el documental D.F. (Destino Final) de Mateo Gutiérrez (Uruguay, 2008). A través de múltiples entrevistas, Gutiérrez rescata la figura de su padre, 
Héctor Gutiérrez Ruiz, diputado y presidente de la Cámara de Representantes, quien fuera secuestrado y asesinado en su exilio bonaerense en 1976 junto al senador Zelmar Michelini y a los ex-militantes del MLN-Tupamaros Rosario Barredo y William Whitelaw. Las declaraciones de los entrevistados, los álbumes de familia, los archivos de prensa van poblando de contenido un silencio que se eleva sobre el perfil fantasmático del padre perdido en la infancia, consolidándolo en su calidad y calidez humana pero también en su conformación como hombre político. Propongo que, por un lado, este gesto permite explorar el límite poroso y maleable existente entre la memoria individual y familiar de un sujeto destacado de la historia uruguaya y la construcción de una narrativa de la memoria de carácter colectivo que ofrece una interpretación del pasado reciente del país. En ese sentido, el destino de Héctor Gutiérrez Ruiz y de su núcleo familiar (replicado en aquel de la familia Michelini y la familia Barredo-Whitelaw) se erige en alegoría de un país silenciado, violentado, mancillado y fragmentado por doce años de dictadura cívicomilitar y un preámbulo no menos ominoso. Por otro, a través de los silencios que el film opta por mantener, vinculados fundamentalmente a los procesos legales asociados a los autores intelectuales y materiales del crimen, nos brinda un acceso privilegiado al acercamiento afectivo del realizador a la necesidad de la recuperación de la memoria traumática y el esclarecimiento de la verdad en los casos de violaciones a los derechos humanos, así como también a las posibilidades y limitaciones del establecimiento de la justicia. En definitiva, el documental D.F. de Mateo Gutiérrez se constituye como un aporte a las «batallas» (Allier Montaño, 2010; Peter Winn 2013: 15) por la recuperación de la memoria del pasado reciente en el Uruguay, constatando una particular «narrativa de la memoria» (Lessa, 2013: 19-20) o «memoria emblemática» (Stern, 2004: 120), en el entendido de que se trata de una forma de dar sentido y articular los eventos del pasado, contrapuesta y/o complementaria de otras interpretaciones provenientes de diferentes agentes sociales.

\section{Memoria, derechos humanos y justicia transicional en Uruguay}

3 Las luchas por el esclarecimiento de los crímenes y de las violaciones a los derechos humanos en el Uruguay de la dictadura, así como también el establecimiento de la justicia transicional, han seguido un camino tortuoso en el país. Desde los inicios del primer gobierno de transición en el año 1985, encabezado por el presidente Julio María Sanguinetti del Partido Colorado, facción política de centro-derecha, fue evidente que su plan de «pacificación nacional» a través del «cambio en paz» albergaba una política de derechos humanos que obstaculizaba los juicios a quienes habían cometido crímenes durante la dictadura y condenaba los hechos al silencio y al olvido (Lessa \& Fried, 2011: $33)^{2}$. Como punto culminante de la política de derechos humanos del Ejecutivo, el presidente Sanguinetti abogaría por la unidad de los partidos tradicionales en torno a la aprobación en el Parlamento de la Ley n..$^{\circ} 15.848$ o Ley de Caducidad de la Pretensión Punitiva del Estado, consagrada el 22 de diciembre de 1986. Esta ley implicaba que los funcionarios policiales y militares responsables de delitos durante la dictadura no podrían ser juzgados y determinaría la clausura y archivo de todos los juicios penales por violaciones a los derechos humanos presentados por víctimas o sus familiares desde abril de 1985 (Lessa \& Fried, 2011: 33-34). 
Una vez aprobada esta ley en el Parlamento, las organizaciones de derechos humanos y otras agrupaciones sociales y políticas anunciaron el inicio de la campaña por el «Voto Verde» para someterla a referéndum con la intención de anularla. Este referéndum tuvo lugar en abril de 1989 y, a pesar de estos esfuerzos, el voto verde fue derrotado en las urnas (Lessa \& Fried, 2011: 36). Este desenlace marcó un punto de inflexión en la forma en que la sociedad uruguaya se relacionaba con el pasado reciente y representó un duro revés para aquellos sectores que habían aunado fuerzas en su reclamo de justicia (la izquierda, los movimientos sociales, la comunidad académica, etc.). El resultado fue un ostensible silencio que marginalizaba las discusiones acerca de la dictadura y su legado, a pesar de los reclamos de aquellos que sostenían la necesidad de mantener vivo este diálogo (Markarian \& Marchesi, 2012: 224)3.

Sin embargo, nuevas coyunturas nacionales, regionales e internacionales determinaron un cambio de rumbo en el procesamiento del pasado reciente (Lessa, 2013: 143). 1996 será un año clave en el devenir de las demandas por verdad y justicia ya que el 20 de mayo se realiza la «Marcha del Silencio», convocada por los familiares de desaparecidos para reclamar el esclarecimiento del destino de estos (Markarian \& Marchesi, 2012: 226). La fecha es por demás significativa ya que se trata, precisamente, de la fecha de los asesinatos en Buenos Aires de Michelini y Gutiérrez Ruiz. El llamado en la prensa del senador Rafael Michelini (hijo de Zelmar Michelini) reunió a miles de personas en el centro de Montevideo y pasó a convertirse en un evento anual que desafía las políticas de impunidad de los años noventa (Lessa, 2013: 143). Esta marcha resume simbólicamente la reinserción progresiva de los temas relacionados con la dictadura en la agenda de discusión pública (Markarian \& Marchesi, 2012: 226).

6 Ya en el nuevo siglo, la prédica y accionar del movimiento de derechos humanos logra tener un impacto en la voluntad política de investigar los crímenes de la dictadura y tramitarlos judicialmente. Índice de esto es el reconocimiento por parte del presidente Jorge Batlle (también del Partido Colorado) al asumir la presidencia en marzo de 2000 acerca de la necesidad de dar una respuesta oficial a las demandas sobre las consecuencias de la represión y, especialmente, sobre la situación de los desaparecidos. Con tal fin, se creó la «Comisión para la Paz», la cual confirmó veintiséis denuncias sobre desapariciones de ciudadanos uruguayos en el país (Markarian \& Marchesi, 2012: 226-227) ${ }^{4}$. No obstante las limitaciones de dicha Comisión, se trató del primer proyecto oficial del Estado uruguayo que reconocía públicamente la existencia de crímenes de lesa humanidad, a pesar de no tener repercusiones legales o judiciales (Lessa \& Fried, 2011: 37). Sin embargo, el gran giro en las políticas oficiales se produciría en el año 2005 al asumir la presidencia el Dr. Tabaré Vázquez, de la coalición de centro-izquierda Encuentro Progresista (Frente Amplio). Entre otras medidas, Vázquez permitió el accionar de la Justicia dentro de las regulaciones legales vigentes, e impulsó la reparación a presos políticos y familiares de desaparecidos y las excavaciones arqueológicas para ubicar restos de los desaparecidos en predios militares (Markarian \& Marchesi, 2012: 227) ${ }^{5}$

7 Al cumplirse veinte años del referéndum de 1989 y a impulso de organizaciones sociales, políticas y sindicales se consolidó otra iniciativa para intentar anular la Ley de Caducidad a través de una reforma constitucional sometida a plebiscito. A pesar de que una amplia cantidad del electorado se manifestó a favor de anular la ley a través del Sí Rosado, los votos no fueron suficientes. Sin embargo, a diferencia de 1989, la derrota del plebiscito no 
cristalizó en silencio sino en nutridos esfuerzos de la sociedad civil para eliminar la ley por otros caminos (Lessa \& Fried, 2011: 37-38).

8 Es importante agregar además que entre 2009 y 2010, en tres oportunidades, en base a pedidos de las fiscales Mirtha Guianze y Ana María Tellechea, la Suprema Corte de Justicia declaró «inconstitucional» la Ley de Caducidad por violar ciertos artículos de la Constitución y por estar en conflicto con convenios internacionales de derechos humanos. La lucha contra esta ley adquiriría ribetes internacionales cuando el poeta argentino Juan Gelman presentara el caso de su nuera y el de su nieta, Macarena, ante la Corte Interamericana de Derechos Humanos con sede en Costa Rica ${ }^{6}$. En 2011, la Corte Interamericana emitió una sentencia condenatoria de Uruguay en la que establecía no solamente que la Ley de Caducidad no podía ser aplicada en este caso particular sino que no debía proceder en ningún otro caso de violación de derechos humanos dada su incompatibilidad con la Convención Americana (Lessa \& Fried, 2011: 40-41).

Luego de un intento fallido en mayo de 2011 (ya durante la presidencia del frenteamplista José Mujica), cinco meses después, a través de un ley interpretativa (Ley n. ${ }^{\circ} 18.831$ ), el Parlamento aprobó la restitución de la pretensión punitiva del Estado para los delitos cometidos durante la dictadura, los declaró imprescriptibles y, de acuerdo con la legislación internacional, los consideró crímenes de lesa humanidad. Sin embargo, en febrero de 2013 la Suprema Corte declaró inconstitucional los artículos 2 y 3 de dicha ley, rechazando la imprescriptibilidad de los delitos y su carácter de crímenes de lesa humanidad (De Giorgi, 2013: 94). Al ser considerados crímenes comunes, y por lo tanto prescriptibles de acuerdo con el código penal nacional, esto implicaría el cierre de todas las investigaciones en curso (Burt \& Lessa, 2013) y una marcha atrás en el proceso de la búsqueda de la verdad y el establecimiento de la justicia.

\section{Una memoria personal y política}

10 Junto a los documentales Secretos de lucha de Maiana Bidegain (Francia, 2007) y Es esa foto de Álvaro Peralta (Uruguay, 2008), D.F. compone un tríptico que ahonda en el salvataje de la memoria del horror de la generación precedente en el caso uruguayo. Bidegain rastrea en la figura de su padre un pasado de militancia y exilio compartido con sus tíos cuyo recuerdo, desdibujado bajo la imagen complaciente de un simple retorno a los orígenes vasco-franceses y una puesta de distancia con respecto a la situación en Uruguay, hasta entonces le había estado vedado. Por su parte, la película de Peralta sigue los pasos de la joven Micaela Rivero Castagnetto en su afán de recabar información sobre su tío materno, Héctor Castagnetto, secuestrado y ejecutado por el Escuadrón de la Muerte, de quien conserva por toda referencia una vaga imagen de una pequeña foto carnet. Aunque buena parte de los documentales producidos por la segunda generación de la dictadura en Argentina y Chile han sido abordados por los académicos a partir del andamiaje teórico de la posmemoria, concepto desarrollado por Marianne Hirsch y sería tentador aplicarlo por igual a las realizaciones uruguayas, coincido con las precisiones realizadas por Beatriz Tadeo Fuica acerca de la imposibilidad de reducir a este término todas las memorias de esta generación (Tadeo Fuica, 2014: 2). El documental de Gutiérrez es particularmente excluido por la crítica de esta categorización. Hirsch define a la posmemoria como:

[...] la relación que la «generación posterior» guarda con el trauma personal, colectivo y cultural de aquellos que los precedieron con experiencias que ellos 
«recuerdan» solamente a través de las historias, imágenes y comportamientos entre los que crecieron (Tadeo Fuica, 2014: 5) ${ }^{7}$.

11 Sin embargo, como señala Tadeo Fuica, Hirsch asocia también a este concepto el distanciamiento, tanto temporal como geográfico, de la nueva generación con respecto al evento traumático. Tal distanciamiento se encuentra ausente en el caso de Mateo Gutiérrez. Gutiérrez tenía seis años de edad cuando fue testigo del secuestro de su padre $\mathrm{y}$, luego de la aparición del cuerpo torturado y fusilado de su padre un par de días después, permaneció viviendo en el clima dictatorial del Cono Sur, lo cual determina que el realizador tenga un archivo personal del hecho traumático que se combina con las memorias de sus mayores (Tadeo Fuica, 2014: 6). Siguiendo nuevamente a Tadeo Fuica, esta particular experiencia vital marca su impronta en las prácticas audiovisuales del director así como también en su relacionamiento con el pasado reciente (Tadeo Fuica, 2014: 2).

12 Esa aproximación única al fenómeno audiovisual y al pasado reciente uruguayo de Mateo Gutiérrez es la que me interesa analizar ahora. Dos son las características que considero definen el acercamiento del director: personal y político. En declaraciones realizadas al diario LaRepública, Gutiérrez reconoce para su documental la primera de las características pero descarta la segunda en su acepción tradicional. Expresa el realizador que la película es «la visión íntima de un hijo que trata de reconstruir la imagen paterna» pero que no se trata de «un trabajo político en el sentido estricto del término» («Necesitamos saber la verdad», La República, 2008). Como afirma Michael Chanan, desde los años setenta surge un nuevo tipo de discurso documental que, afirmado en la realidad social, «reivindica la prerrogativa del cineasta de expresar su propia visión del mundo», en su calidad de ciudadano del mismo (Chanan, 2007: 12). Por otra parte, Chanan sostiene la habilidad del documental para hacer frente a los desafíos políticos en la medida en que la política «está en sus genes» (Chanan, 2007: 16). Sin embargo, tampoco se refiere a una función política que implique defender una posición ideológica o abogar por una causa sino simplemente a la capacidad del documental para «atraer la atención pública a sus temas y preocupaciones, a veces simplemente sacándolos a la luz», evidenciándose como un síntoma saludable del «retorno a la realidad» (ibíd.). En un cierto sentido, esta concepción se aproxima a aquella de cine «impolítico» de Teresa Vilarós, en el que se rehuye toda inscripción en y explicación de la realidad a través de narrativas totalizantes (Vilarós, 2010: 518), lo que no excluye su carácter comprometido y crítico. Este cine ha sido definido por Elixabete Ansa Goicochea y Óscar Ariel Cabezas como aquellas producciones cinemáticas que provocan, en «la economía de la mirada», un «quiebre en las convencionalidades del acto de ver», una fractura en «la mirada voyerista y comercial» (Ansa Goicochea \& Cabezas, 2014: 11). El documental de Marcos Gutiérrez es eminentemente personal en la medida en que aborda su universo privado sin borrar del film las marcas de su presencia estructurante que pauta una cierta interpretación del pasado reciente. $\mathrm{Y}$ es marcadamente político (en las acepciones manejadas por Chanan y Vilarós) en cuanto descuadra el «habitus de la mirada» (ibíd.) haciendo al espectador partícipe en la reflexión acerca de la recuperación de la memoria traumática, la necesidad de conocer y registrar la verdad, así como los alcances y limitaciones del establecimiento de la justicia. 


\section{Difusión, recepción y modos cinemáticos}

13 El film de Gutiérrez fue estrenado en Montevideo en la sala Grupocine, Torre de los Profesionales, el 30 de mayo de 2008 («Conmovedor filme sobre la vida y muerte de Héctor Gutiérrez Ruíz», La República, 2008). El documental formó parte también de la cartelera de «Efecto Cine», muestra cinematográfica de carácter itinerante organizada por la productora Coral Films que de enero a abril de 2009 («Seis filmes uruguayos en el interior», La República, 2008) recorrió la periferia de Montevideo y el interior del país con el objetivo de difundir la producción nacional y acercar al espectador a las peculiaridades de la creación audiovisual («Empieza hoy la muestra Efecto Cine», La República, 2008) ${ }^{8}$. Por otra parte, en abril de 2009, D.F. fue exhibida en el XII Festival de Cine de Punta del Este y se integró a la muestra itinerante de dicho festival que se desarrolló en el departamento de Maldonado y que trasladó la película a las localidades de Garzón y Solís («Se inaugura hoy el XII festival de cine de Punta», La República, 2009). Además, significativamente, fue una de las cuatro películas uruguayas sobre el tema de la dictadura y los desaparecidos proyectadas en mayo y junio de 2015 en la Muestra de Cine organizada por Madres y Familiares de Desaparecidos con motivo de los veinte años de la Marcha del Silencio, tanto en la capital como en departamentos del interior del país («Madres y familiares de desaparecidos organizan muestra de cine», La República, 2015) ${ }^{9}$. En el año 2008, la película fue galardonada con varios premios otorgados por la Asociación de Críticos del Uruguay: Mejor Película Nacional, Ópera Prima, Mejor Documental Uruguayo y Revelación Masculina para Mateo Gutiérrez («Los filmes destacados de este año», La República, 2008).

De acuerdo a la clasificación de los tipos de documental realizada por Bill Nichols, desde el punto de vista de los modelos ya existentes que el film comparte con la economía de otros medios, D.F. se apoya en el discurso del informe de investigación (Nichols, 2010: 149), la historia (150), el testimonio (151) y la autobiografía (153). En lo que respecta a los modos cinemáticos particulares adoptados por la película, la misma se caracteriza por su carácter participatorio, brindado por el relacionamiento activo del director con sus actores sociales (151).

D.F. Destino Final se compone de veinticinco entrevistas a familiares de las víctimas, amigos y compañeros de militancia política. El material visual y auditivo se completa con aportes de archivos familiares, así como también materiales procedentes de Cinemateca Uruguaya, Canal 4, el Archivo General de la Nación de la República Argentina y archivos policiales uruguayos y argentinos («Necesitamos saber la verdad», La República, 2008). Las entrevistas, caracterizadas por los primeros planos, se intercalan de manera fragmentaria, construyendo diálogos o asociándose por temáticas, y sólo muestran las respuestas, excluyéndose las preguntas que les realizará Gutiérrez. Sin embargo, su figura invisible se cuela subrepticiamente en la cinta a través del registro auditivo de pequeños comentarios, clarificaciones o reacciones a las declaraciones y, significativamente, a través del uso por parte de los entrevistados de pronombres posesivos («tu abuela», Matilde Gutiérrez; «tu padre», Juan Carlos Furest, etc.) que lo subsumen e integran a la trama familiar y, por ende, al drama familiar que memorializa el documental. 


\section{Familia, comunidad y búsqueda de la verdad}

Las dos primeras escenas de este documental son particularmente relevantes en la medida en que postulan cómo el film quiere ser leído. El trabajo de Gutiérrez se abre con un texto impreso escrito en letras blancas sobre fondo negro que registra la siguiente leyenda:

En Mayo de 1976, en Buenos Aires aparece muerto mi padre, Héctor Gutiérrez Ruiz, Presidente de la Cámara de Diputados junto al Senador Zelmar Michelini y a los extupamaros William Whitelaw y su mujer Rosario Barredo. Todos uruguayos. (D.F.)

Del texto se desprende la preeminencia de dos palabras claves para entender el film: familia y comunidad. En su calidad de hijo en el seno de una familia devastada por la muerte del padre, Gutiérrez emprende la tarea de recuperación de la imagen paterna. Sin embargo, con gran delicadeza, no olvida el acercamiento a las figuras de Michelini y Barredo-Whitelaw, en cuyas familias también tuviera eco el dolor y la desolación de la pérdida en circunstancias de violencia política extrema, ya que, como bien sintetiza el politólogo Adolfo Garcé: «Es la tragedia de una familia que en el fondo es la tragedia de un país» («D.F. Destino Final: documental de Mateo Gutiérrez sobre la vida de su padre», Espectador.com, 2008). Esta reflexión nos conduce al segundo término aludido en la leyenda. Gutiérrez destaca la calidad de uruguayos que liga a las víctimas del crimen. Más allá de posicionamientos ideológicos y filiaciones políticas, las víctimas y sus familias son parte integrante de una comunidad asolada por el terrorismo de Estado. El drama de los Gutiérrez es icónico de una situación repetida hasta el hartazgo en una sociedad en la que se han perdido las garantías constitucionales y el respeto por los derechos humanos. Por otra parte, es significativo el hecho de que los parlamentarios asesinados, además de pertenecer a la clase política, estaban vinculados en su origen a los partidos tradicionales: Gutiérrez Ruiz pertenecía al Partido Nacional y Zelmar Michelini, integrante del Frente Amplio, había comenzado su carrera política en el Partido Colorado, al que estaba estrechamente ligado. Esta constatación revela la magnitud de las prácticas represivas del régimen cuyos objetivos de aniquilación iban más allá de la izquierda radical para extenderse, trascendiendo los límites político-ideológicos, a todo actor en defensa de las libertades democráticas.

La segunda de las escenas del film pauta también una manera de aproximarse a la narración construida en el documental. Se trata de imágenes de archivo que muestran a Matilde Rodríguez de Gutiérrez Ruiz, la madre del director, realizando una declaración testimonial en la causa a los miembros de las tres primeras juntas del llamado Proceso de Reorganización Nacional en Buenos Aires en 1985. La selección del fragmento no es casual. Al aportar información sobre el secuestro y asesinato de su esposo, Matilde Rodríguez declara «bajo juramento de decir verdad», con la aclaración de que «afirmar una falsedad o callar la verdad en todo o en parte» será castigado con pena de reclusión o prisión. Ella jura «decir la verdad en todo cuanto supiese y le fuese preguntado». En imágenes del juicio intercaladas en un momento posterior del film, se le pregunta si, una vez secuestrado su marido, «tuvo alguna noticia concreta de dónde podría hallarse [...] por esos momentos». A esto responde que un periodista uruguayo, el Sr. Julio Traibel, vinculado a la Casa de Gobierno de Argentina, «decía saber que él estaba en una dependencia militar. Recuerdo algo así como una dependencia militar que se denominaba con una $\mathrm{D}$ y una $\mathrm{F}$, que se interpretaba como que podía ser "Destino Final". Lo recuerdo como un comentario, no es 
una cosa demasiado clara en mi mente» (el énfasis es mío). Las citas anteriores puntualizan que uno de los objetivos de este documental es registrar la necesidad de esclarecer la verdad acerca de los crímenes cometidos durante el periodo dictatorial, planteando un panorama lo más completo y fidedigno posible, sensible a los hechos contundentes pero también a las incertidumbres y a las lagunas del recuerdo. En las declaraciones realizadas al diario La República, Mateo Gutiérrez explicita esta necesidad de «saber qué pasó y vislumbrar bien la verdad», así como también de «contarle a las nuevas generaciones quién era Héctor Gutiérrez Ruiz» («Necesitamos saber la verdad», La República, 2008).

En ese sentido, y a diferencia de otras producciones audiovisuales del Cono Sur que abordan el tema de la recuperación de la memoria del período dictatorial, el trabajo de Gutiérrez no cuestiona el estatuto de «verdad», la posibilidad de acercarse a una memoria completa, fehaciente y sin fisuras, y las limitaciones del género documental para dar cuenta del pasado. Es sobre todo notorio el contraste con uno de los filmes posdictatoriales de la segunda generación mencionados en la introducción de este trabajo. Me refiero específicamente a Los rubios de Albertina Carri. A través de la reflexión metaficticia, el recurso a la animación y otras estrategias cinemáticas, Carri pone de manifiesto «las falacias de la memoria, la centralidad de la subjetividad, la tenuidad y multiplicidad de la verdad, las intersecciones entre las formas del discurso privado y público y el carácter de "construcción" textual de todas las representaciones del pasado" (Lazzara, 2009: 149). Las propias declaraciones de Carri para el documental confirman y refuerzan esa postura:

La familia, cuando puede sortear el dolor de la ausencia, recuerda de una manera en que mamá y papá se convierten en personas excepcionales, lindos, inteligentes. Los amigos de mis padres estructuran el recuerdo de forma tal que todo se convierte en un análisis político. [...] Lo único que tengo es mi recuerdo difuso y contaminado por todas estas versiones. Creo que cualquier intento que haga de acercarme a la verdad, voy a estar alejándome.

En contraste, por medio de un estilo documental más tradicional, Gutiérrez se limita a insistir en la necesidad de recuperar el pasado dictatorial, sin problematizar ese ejercicio de memoria.

21 Sin embargo, el afán del realizador de reconstruir una imagen personal e intimista de su padre a través de los testimonios de familiares y amigos sí acerca su óptica a la de otros directores de la segunda generación posdictatorial. Surge así la imagen del niño tímido, que se ruborizaba con facilidad (Ricardo Vidal), huérfano a muy temprana edad (Matilde Rodríguez), que deviene en orador con «una gran facilidad de expresión» y una «voz magnífica», cuyo discurso, en el que se mezclaba la filosofía con la cultura popular, «seducía, convencía, arrastraba» (Alberto Volonté). Es luego el adulto amante de la vida del campo (Matilde Rodríguez), el mate (Mario Capurro), la hípica (Alberto Volonté) y la música de Alfredo Zitarrosa (Juan Pablo Gutiérrez), el padre que se emociona ante el despliegue de vida que representan los juguetes desperdigados de sus hijos (Matilde Rodríguez), el experto en el Vaticano y en diferentes logias (Federico Fasano), el eterno optimista (Mario Capurro).

Si otras obras cinemáticas de jóvenes de la segunda generación exploran, ponderan y, en algunos casos, cuestionan las opciones de militancia o resistencia política de sus padres $y$, fundamentalmente, sus repercusiones en el entorno familiar y en la vida de los hijos fundamentalmente, las experiencias vitales de Mateo Gutiérrez en su calidad de partícipe del trauma del secuestro y muerte de su padre, así como también de la represión 
dictatorial en el Cono Sur, le orientan en otra dirección. Portador de un marco referencial otorgado por la experiencia activa del horror, el realizador opta por rastrear el surgimiento, desarrollo y consolidación de su padre como hombre político, sin olvidar hacer lo propio con la figura de Michelini y de la pareja Barredo-Whitelaw. El film, de una hora y cincuenta y dos minutos de duración, explicita de esta manera la concientización de que, para poder comprender la narrativa de la verdad propuesta por el documental, es necesario contar con la necesaria contextualización, especialmente de cara a las generaciones presentes y futuras que no cuentan con archivos mnemónicos personales de los años de la dictadura y de los que la precedieron inmediatamente. Héctor Gutiérrez Ruiz es presentado como un marcado antiimperialista con una base popular y nacionalista, quien, con el inicio de la turbulencia política en el país, pone el futuro del Uruguay por encima de «la pequeña vanidad de los hombres» (discurso, Héctor Gutiérrez Ruiz), clama por el fin del estado de guerra decretado por el presidente Bordaberry, destacando la inutilidad e ineptitud de las medidas extremas adoptadas por el gobierno $y$, una vez instaurada la dictadura, denuncia internacionalmente las violaciones a los derechos humanos y realiza gestiones para concretar el retorno a la democracia.

Tanto Gutiérrez Ruiz como Michelini formaban parte de un activo grupo de exiliados uruguayos en Buenos Aires abocados a denunciar los abusos del regimen frente a organizaciones internacionales y gobiernos extranjeros (Markarian, 2005: 75-76) ${ }^{10}$. A este respecto, en noviembre de 1975, Gutiérrez Ruiz concretó un viaje para presentar el caso uruguayo ante el Parlamento Europeo (Markarian, 2005: 206). Por su parte, Michelini declaró ante el Tribunal Bertrand Russell en Roma en abril de 1974, e hizo ingentes esfuerzos por dirigirse al gobierno estadounidense, sobre todo a su Parlamento, además de colaborar con organizaciones tales como Amnistía Internacional, la Cruz Roja y la Comisión Internacional de Juristas, entre otras iniciativas (Markarian, 2005: 76, 78-79) ${ }^{11}$. En síntesis, tanto Gutiérrez Ruiz como Michelini bregaron porque las atrocidades del régimen uruguayo fueran conocidas fuera de fronteras y la presión internacional coadyuvara en la restauración del sistema democrático en el país.

\section{Narrativas de la verdad}

El foco del film en la necesidad y la posibilidad de esclarecer la verdad sobre los hechos ocurridos se intensifica y explicita hacia el final del documental a través de las declaraciones de Matilde Rodríguez y Gabriela Schroeder, hija mayor de Rosario Barredo que fuera secuestrada junto a su madre, Whitelaw y sus hermanos, así como también el testimonio en el Juicio a las juntas militares argentinas del periodista uruguayo Enrique Rodríguez Larreta y de su hijo del mismo nombre. Estos aportes señalan la presencia de los argentinos Aníbal Gordon y Osvaldo «Paqui» Forese en el secuestro de Héctor Gutiérrez Ruíz, dejan constancia de la presencia de la familia Barredo-Whitelaw en el centro clandestino de detención Automotores Orletti (situado a corta distancia del lugar donde apareciera el coche con los cuerpos de las cuatro víctimas), al tiempo que evidencian la participación de oficiales militares uruguayos en los interrogatorios y sesiones de tortura realizados en dicho centro, concretamente el «Turco» Arab, el Capitán Manuel Cordero y el Mayor José Nino Gavazzo, y la existencia de la coordinación de las fuerzas represivas en el Cono Sur. Material fotográfico que incluye a Amaury Prantl, Jefe del Servicio de Inteligencia del Ejército uruguayo, así como también a Carlos Suárez 
Mason, Jefe del Cuerpo n. ${ }^{\circ} 1$ del Ejército argentino y a Otto Paladino, Secretario de Inteligencia del Estado argentino, complementa estas informaciones.

La contundencia de estas declaraciones arroja nueva luz sobre el fragmento de la entrevista al ex presidente Julio María Sanguinetti integrado en el film, el cual adquiere una especial relevancia ya que, como ha señalado Álvaro de Giorgi, «Sanguinetti fue el principal creador, artífice y hábil exponente de una historia oficial del pasado reciente en Uruguay a partir de 1985, desafiada por múltiples discursos alternativos» (De Giorgi, 2014: $15)^{12}$. Uno de los principales preceptos de su filosofía acerca de este pasado reciente y el futuro posdictatorial se resume en su sonada frase en la que reclamaba que no había que tener «ojos en la nuca». Según esta concepción, para reafirmar la paz y consolidar el futuro, el pasado debía ser olvidado y no ser sometido a análisis, reconsideración o investigación (Lessa, 2013: 176).

Es en este marco ideológico que las declaraciones de Sanguinetti para la entrevista que integra el documental deben ser consideradas. Al referirse al secuestro y asesinato de los legisladores Héctor Gutiérrez Ruíz y Zelmar Michelini, Sanguinetti insiste en la imposibilidad de afirmar fehacientemente el grado de implicación uruguaya en los hechos $\mathrm{y}$, a pesar de haberse realizado durante su mandato una investigación parlamentaria, una cierta impotencia para esclarecer lo sucedido ya que los acontecimientos habían tenido lugar en Argentina. No casualmente, éste es el único intercambio de Mateo Gutiérrez con un entrevistado en el que su presencia no aparece velada y en el que, a pesar de que no se percibe su imagen, su participación activa se revela a través de preguntas y comentarios tendientes a elucidar la verdad. Las declaraciones de Sanguinetti se ven complementadas por el fragmento de la entrevista a Danilo Arbilla en el que éste afirma que la investigación parlamentaria durante el primer mandato de Sanguinetti se vio frustrada por una maniobra del gobierno.

Significativamente, aparece en pantalla a continuación un texto impreso en letras blancas sobre fondo negro con la siguiente leyenda: «En diciembre de 1986 se votó la Ley de Caducidad para amnistiar a los militares de los hechos ocurridos en la dictadura». Como señala Gabriela Fried, esta ley representó el punto culminante de una «política de Olvido», «un pacto político [...] destinado a sustentar una "transición en paz" a través de un programa de reconciliación social basado en la amnistía y la amnesia social [...] “dando vuelta la página" al conflicto social y la violencia del pasado reciente» (Fried, 2011: 160). Volviendo al documental, posteriormente, luego de la inclusión de un mapa en el que se marca la ubicación de la intersección en la que apareciera el coche con los cuatro cadáveres y de Automotores Orletti, en uno de los momentos más emotivos y perturbadores del film, se muestran una a una, acompañadas de sus nombres de pila, las fotos de los cuerpos maltratados y ejecutados de las cuatro víctimas. La última foto en aparecer es la de Héctor Gutiérrez Ruiz, junto a la leyenda: «mi viejo». Desprovistos de sus apellidos, filiaciones políticas, cargos, etc., los cuatro se reinsertan en una comunidad en la que, en su calidad de ciudadanos uruguayos y miembros de un núcleo familiar del que han sido arrancados, simbolizan a los múltiples desaparecidos, encarcelados, torturados, y asesinados causados por el terrorismo de Estado, y en la que, más allá de limitaciones legales y otros obstáculos, la necesidad de saber y consignar la verdad sobre el pasado se hace imperativo para la construcción de un presente y un futuro posibles.

Tal como señala Francesca Lessa, basándose en investigaciones de Hayner y Barahona de Brito, con el advenimiento de la democracia, y a pesar del desinterés del gobierno colorado y sus posteriores intentos de obstrucción (como ya he indicado anteriormente), 
la Cámara de Representantes inició en 1985 una Comisión Investigadora del Secuestro y Asesinato de los Representantes Nacionales Zelmar Michelini y Héctor Gutiérrez Ruiz. Si bien la misma logró recoger importantes informaciones y testimonios, debido a las limitaciones en sus recursos y en sus poderes, no pudo encontrar evidencias contundentes que probaran la responsabilidad institucional que condujera a las violaciones cometidas. De hecho, el presidente Sanguinetti, en una vena similar a sus declaraciones para el documental, desestimó los hallazgos de la comisión por considerar que no clarificaban la autoría de los crímenes ni aportaban conclusiones creíbles (Lessa, 2013: 135). Para frenar el trabajo de la Comisión, ciertas actas habrían sido filtradas a la prensa (publicadas por el diario El País, concretamente). En ellas, la declaración de dos testigos sugeriría que el Coronel Pedro Mato del ejército uruguayo habría viajado a Buenos Aires acompañado por Manuel Cordero y sería el autor material del asesinato del Senador Michelini (Melgar Hourcade, 2006: 181 y 203-204).

La aprobación de la Ley de Caducidad en diciembre de 1986, ratificada popularmente en el referéndum de 1989 y el plebiscito del 2009, pondrá fin a ulteriores investigaciones hasta que (como ya he adelantado) en su discurso inaugural de asunción del mando en marzo del 2005, el Presidente Tabaré Vázquez, primer mandatario perteneciente a un partido de izquierda del país, excluya específicamente estos crímenes de la Ley de Impunidad (Lessa, 2013: 148). Como consecuencia de la reapertura del expediente judicial, a petición del diputado Felipe Michelini, hijo de Zelmar Michelini, en noviembre del 2002 (Allier Montaño, 2010: 236), el 16 de noviembre de 2006, previa solicitud de la fiscal Mirtha Guianze, el juez Roberto Timbal dispuso el procesamiento con prisión del ex dictador Juan María Bordaberry y de su canciller Juan Carlos Blanco, por coautoría de cuatro homicidios muy especialmente agravados (De León Orpi, 2011: 185-186). Esta decisión se traduciría en junio del año 2011 en una condena a treinta años de prisión por tal motivo («Juez no alcanzó a notificar a Bordaberry», La República, 2011).

Como indica Carlos Demasi, los cuatro crímenes pueden ser identificados como asesinatos «tácticos» en la medida en que apuntaban a poner freno a una serie de acercamientos entre personas allegadas al régimen dictatorial, entre ellos, el Ministro de Economía Alejandro Végh Villegas y los políticos para consolidar una salida (Demasi, 2009: 45-46). De 1974 a 1976, Végh Villegas diseñó las nuevas políticas neoliberales del sistema. Sin embargo, el economista sentía cierto malestar acerca de la ascendiente ilegitimidad del gobierno y consideraba que, para asegurar un régimen perdurable, el consenso cívico era esencial. Si bien no promovía un retorno rápido a un gobierno democrático, sí impulsaba el mantenimiento de ciertos «mecanismos políticos formales». Con tal fin, había intentado entrar en contacto con líderes de la oposición residentes en Buenos Aires, iniciativa fuertemente rechazada por muchos miembros del estamento militar (Markarian, 2005: 82-83). Pocos días antes de los asesinatos, Végh Villegas se había reunido con Michelini en una confitería bonaerense para proponerle una «salida» con una etapa de transición, solución que contaba, según el economista, con apoyo de militares y políticos. En esta iniciativa «Michelini, Gutiérrez Ruiz y Wilson [Ferreira Aldunate] eran las piezas clave para esa salida, para la dictadura la vida de los legisladores era el máximo peligro para su continuidad» (De León Orpi, 2011: 186).

31 En lo que respecta a las investigaciones sobre el caso de los parlamentarios y los ciudadanos Barredo y Whitelaw en Argentina, con el retorno a la democracia en este país, el ex dictador Jorge Rafael Videla había sido condenado durante el juicio a las Juntas militares por el homicidio agravado de los cuatro uruguayos (Melgar Hourcade, 2006: 35). 
En el año 2004, impulsadas por las nuevas políticas de justicia avaladas por el presidente Néstor Kirchner, las familias de Michelini y Gutiérrez Ruiz habían llevado adelante en la capital argentina una denuncia por los crímenes cometidos en 1976 (Allier Montaño, 2010: 236-237) en el afán de profundizar en los hechos ocurridos. En consecuencia, el ex general Guillermo Suárez Mason y el general Jorge Olivera [Róvere] fueron procesados por coautoría de los homicidios, y fueron acusados los uruguayos Juan M. Bordaberry y Juan C. Blanco junto a dieciséis militares, también uruguayos (De León Orpi, 2011: 184). Olivera Róvere, adjunto del fallecido Suárez Mason, sería condenado a cadena perpetua en el año 2009 por estos asesinatos y otros delitos de lesa humanidad («Condenan a ex militar argentino», Espectador.com, 2009).

\section{Memorias y olvidos}

Al considerar el tema de la memoria, Elizabeth Jelin señala:

Toda política de conservación y de memoria, al seleccionar huellas para preservar, conservar o conmemorar, tiene implícita una voluntad de olvido. Esto incluye, por supuesto, a los propios historiadores e investigadores que eligen qué contar, qué representar o qué escribir en un relato. (Jelin, 2002: 30)

En el marco de esta afirmación, resulta útil reflexionar sobre el hecho de que, en el documental de Mateo Gutiérrez, no se hacen referencias concretas a los juicios específicos por los crímenes cometidos ni a los procesamientos que estos desencadenaron. Estas borraduras son por demás significativas y creo que apuntan a una doble interpretación del pasado reciente y de los alcances y limitaciones de la justicia transicional en el país. En primer lugar, los asesinatos de Gutiérrez Ruiz y Michelini tienen para el Uruguay una dimensión simbólica que engloba a todos aquellos ciudadanos víctimas de la violencia de Estado. Dar por cerrado un ciclo a través de los procesamientos realizados por el crimen de los políticos implicaría soslayar que, dada la vigencia de la Ley de Caducidad, múltiples otros delitos quedan aún por aclarar y juzgar. Prueba de este carácter simbólico de la figura de los parlamentarios es la Marcha del Silencio que, desde 1996, cada 20 de mayo recuerda a los desaparecidos y la necesidad de esclarecer su situación. Pero, por otro lado, este silenciamiento tiene también como objetivo subrayar, empleando aquí la terminología acuñada por Michael Lazzara, los «restos» que aún permanecen al cerrarse un procedimiento judicial y dictarse un veredicto. Basándose en investigaciones de Nancy Rosemblum, Lazzara señala que, desde el punto de vista de las víctimas, si bien la importancia de los juicios queda fuera de toda discusión, estos pueden ser inadecuados ya que muchas veces no se reúne suficiente información como para brindar un panorama completo de los hechos o no se ajustan a las necesidades afectivas o psicológicas de los afectados (Lazzara, 2011: 90). Creo que, en el caso presentado por D.F., ambos tipos de «restos» se encuentran presentes. Dado el camino sinuoso de la justicia transicional en el Uruguay, marcado fundamentalmente por la vigencia de la Ley de Caducidad, son muchas las informaciones sobre los asesinatos que aún permanecen sin ser reveladas, y varias las responsabilidades aún por esclarecer. Por otra parte, tal como indica Lazzara recuperando las palabras de Idelver Abelar, ante la experiencia traumática, el trabajo del duelo es una tarea que nunca acaba por completarse y que se extiende ad infinitum (Lazzara, 2011: 90). En base a las conclusiones anteriores, coincido con Beatriz Tadeo Fuica cuando señala que, al invisibilizar las sentencias, Mateo Gutiérrez pone el énfasis en el proceso (Tadeo Fuica, 2015: 11). Esta apreciación se ve confirmada por las propias declaraciones de Gutiérrez, que señala para el diario La República que «me da miedo que 
los enjuiciamientos le pongan punto final a un proceso que en realidad no terminó» («Necesitamos saber la verdad», La República, 2008).

Para concluir, es posible señalar que el documental de Mateo Gutiérrez, desde su ángulo personal, intimista y político, constituye un aporte particular a la circulación de discursos sobre el pasado reciente en el Uruguay y sus disputas por el poder de representación de la experiencia del trauma que significaron los doce años de dictadura y la convulsión de los años inmediatamente precedentes, así como también de los caminos transitados por la justicia transicional. Este testimonio gráfico, que a partir de la recuperación de la figura individual de su padre, el diputado Héctor Gutiérrez Ruiz, asume un carácter comunitario, es clara evidencia de que, en la cultura visual, la ausencia de ciertas imágenes es tanto o más significativa que la inclusión de otras. Los fotogramas que integran el documental dan cuenta de la necesidad de saber y consignar la verdad acerca de las violaciones a los derechos humanos. Los excluidos, específicamente aquellos vinculados a los juicios y procesamientos a los responsables intelectuales de los crímenes a los políticos, tienen un doble alcance que pone de relevancia los residuos que quedan presentes al cerrarse el proceso legal. A nivel colectivo, dada aún la vigencia de la Ley de Caducidad que impide juzgar la totalidad de los delitos cometidos, son muchos aún los casos de otros ciudadanos uruguayos que quedan por esclarecer. A nivel personal, y por los mismos motivos, se destaca la carencia de un panorama completo de informaciones sobre los hechos acontecidos en Buenos Aires, lo que se suma al trabajo permanente del duelo por la pérdida sufrida. Por todas estas causas, el asesinato de los cuatro uruguayos es una herida sin suturar en la epidermis de la sociedad nacional que reclama la labor constante de la memoria.

\section{BIBLIOGRAFÍA}

ALliER MontaÑo Eugenia (2010), Batallas por la memoria. Los usos políticos del pasado reciente en Uruguay, Montevideo: Trilce.

ANSA GoICOECHEA Elixabete \& CABEZAS Óscar Ariel (eds.) (2014), Efectos de imagen. ¿Quéfue y qué es el cine militante?, Santiago de Chile: LOM.

BURT Jo-Marie \& LESSA Francesca (2013), «Reciente sentencia de la Suprema Corte Uruguaya obstruye búsqueda de verdad y justicia», WOLA. Advocacy for Human Rights in the Americas, < www.wola.org/es/comentario/ reciente_sentencia_de_la_suprema_corte_uruguaya_obstruye_la_busqueda_de_verdad_y_justicia $>$ [consultado el 30/01/2016].

CHANAN Michael (2007), The Politics of Documentary, London: British Film Institute.

«Condenan a ex militar argentino a cadena perpetua», Espectador.com, 23 octubre 2009, < www.espectador.com/sociedad/165250/condenan-a-ex-militar-argentino-a-cadena-perpetua> [consultado el 05/02/2011]. 
«Conmovedor filme sobre la vida y muerte de Héctor Gutiérrez Ruíz», La República, 30 mayo 2008, $<$ www.lr21.com.uy/cultura/312985-conmovedor-filme-sobre-la-vida-y-muerte-de-hectorgutierrez-ruiz> [consultado 26/01/2016].

DE GIORGI Álvaro (2014), Sanguinetti. La otra historia del pasado reciente, Montevideo: Fin de Siglo.

DE GIORGI Ana Laura (2013), «El Frente Amplio y su laberinto. La izquierda uruguaya frente a la Ley de Caducidad», A. Marchesi (org.), Ley de Caducidad. Un tema inconcluso. Momentos, actores y argumentos (1986-2013), Montevideo: Trilce, 61-102.

DE LEÓN ORPI Walter (2011), «Juan María Bordaberry: el dictador latinoamericano condenado por delitos de lesa humanidad», G. Fried \& F. Lessa (comps.), Luchas contra la impunidad: Uruguay, 1985-2011, Montevideo: Trilce, 175-188.

Demasi Carlos (2009), «La evolución del campo político en la dictadura», C. Demasi, A. Marchesi, V. Markarian, Á. Rico \& J. Yaffé, La dictadura cívico-militar. Uruguay 1973-1985, Montevideo: CEIUBanda Oriental, 17-84.

D.F. (Destino Final), dir. Mateo Gutiérrez, 2008, DVD.

«D.F. Destino Final: documental de Mateo Gutiérrez sobre la vida de su padre, Héctor Gutiérrez Ruiz», Espectador.com, 16 junio 2008, <www.espectador.com/politica/124571/d-f-destino-finaldocumental-de-mateo-gutierrez-sobre-la-vida-de-su-padre-hector-gutierrez-ruiz $>$ [consultado el 16/01/2015].

Efecto Cine, Calendario de Cine Nacional 2008/2009, <www.efectocine.com/uc_158_1.html> [consultado el 26/01/2016].

«Empieza hoy la muestra Efecto Cine», La República, 12 diciembre 2008, <www.lr21.com.uy/ cultura/344721-empieza-hoy-la-muestra-efecto-cine> [consultado el 26/01/2016].

Encontrando a Víctor, dir. Natalia Bruschtein, 2005, DVD.

ERLL Astrid (2011), Memory in Culture, New York: Palgrave MacMillan.

Es esa foto, dir. Álvaro Peralta, 2008, DVD.

FRIED AMILIVIA Gabriela (2011), «Private Transmission of Traumatic Memories of the Disappeared in the Context of Transitional Politics of Oblivion in Uruguay (1973-2001): "Pedagogies of Horror" among Uruguayan Families», V. Druliolle \& F. Lessa (eds.), The Memory of State Terrorism in the Southern Cone, New York: Palgrave Macmillan, 160-177.

HIRSCH Marianne (2012), The Generation of Postmemory. Writing and Visual Culture After the Holocaust, New York: Columbia University Press.

JELIN Elizabeth (2002), Los trabajos de la memoria, Madrid: Siglo Veintiuno.

«Juez no alcanzó a notificar a Bordaberry fallo condenatorio», La República, 23 de julio 2011, < www.lr21.com.uy/politica/463985-juez-no-alcanzo-a-notificar-a-bordaberry-fallo-condenatorio> [consultado el 05/02/2016].

LAzZARA Michael J. (2009), «Filming Loss: (Post-)Memory, Subjectivity, and the Performance of Failure in Recent Argentine Documentary Films», Latin American Perspectives, 36(5), 147-157.

LAzZARA Michael J. (2011), «Justice and Its Remainders: Diamela Eltit's Puño y letra», V. Druliolle \& F. Lessa (eds.), The Memory of State Terrorism in the Southern Cone: Argentina, Chile and Uruguay, New York: Palgrave Macmillan, 87-106.

LESSA Francesca (2013), Memory and Transitional Justice in Argentina and Uruguay, New York: Palgrave Macmillan. 
LESSA Francesca \& FRIED Gabriela (2011), «Las múltiples máscaras de la impunidad: la Ley de Caducidad, desde el Sí Rosado hasta los desarrollos recientes», G. Fried \& F. Lessa (comps.), Luchas contra la impunidad: Uruguay, 1985-2011, Montevideo: Trilce, 31-44.

«Los filmes destacados de este año», La República, 26 de diciembre 2008, <www.lr21.com.uy/ cultura/346569-los-filmes-destacados-de-este-ano> [consultado el 26 enero 2016].

Los rubios, dir. Albertina Carri, 2003, DVD.

M, dir. Nicolás Prividera, 2007, DVD.

«Madres y familiares de desaparecidos organizan muestra de cine», La República, 29 abril 2015, < www.lr21.com.uy/cultura/1229948-dictadura-marcha-silencio-20-anos-muestra-cinedocumental-familiares-desaparecidos> [consultado el 26/01/2016].

MARKARIAN Vania (2005), Left in Transformation. Uruguayan Exiles and the Latin American Human Rights Networks, 1967-1984, New York \& London: Routledge.

MARKARIAN Vania \& MARCHESI Aldo (2012), «Cinco décadas de estudios sobre la crisis, la democracia y el autoritarismo en Uruguay», Contemporánea. Historia y problemas del siglo XX, 3 , 213-242.

MELGAR HoURCADE Florencia (2006), Sabotaje a la verdad. ¿Por qué se frustró la investigación parlamentaria en los asesinatos de Michelini y Gutiérrez Ruiz? ¿Quién y por qué reveló información secreta?, Montevideo: Planeta.

Mi vida con Carlos, dir. Germán Berger, 2010, DVD.

«Necesitamos saber la verdad, necesitamos saber qué pasó», La República (La Red21), 22 mayo 2008, <www.lr21.com.uy/cultura/312115-necesitamos-saber-la-verdad-necesitamos-saber-quepaso $>$ [consultado el 16/01/2015].

Nichols Bill (2010), Introduction to Documentary, Bloomington \& Indianapolis: Indiana University Press.

Papá Iván, dir. María Inés Roque, 2004, DVD.

Secretos de lucha, dir. Maiana Bidegain, 2007, DVD.

«Se inaugura hoy el XII festival de cine de Punta», La República, 18 abril 2009. <www.lr21.com.uy/ cultura/360548-se-inaugura-hoy-el-xii-festival-de-cine-de-punta> [consultado el 26/01/2016].

«Seis filmes uruguayos en el interior», La República, 25 octubre 2008, <www.lr21.com.uy/ cultura/336523-seis-filmes-uruguayos-en-el-interior> [consultado el 26/01/2016].

STERN Steve J. (2004), Remembering Pinochet's Chile. On the Eve of London 1998, Durham, NC: Duke University Press.

TADEO FuICA Beatriz (2015), «Memory of Postmemory? Documentaries Directed by Uruguay's Second Generation», Memory Studies, 8(3), 298-312.

VILARós Teresa (2010), «Barcelona come piedras. La impolítica mirada de Jacinto Esteva y Joaquín Jorda en Dante no es únicamente severo», Hispanic Review, 78(4), 513-528.

WINN Peter (2013), «Prefacio. La batalla por la memoria histórica», S. Stern, P. Winn, F. Lorenz \& A. Marchesi, No hay mañana sin ayer. Batallas por la memoria histórica en el Cono Sur, Lima: IEP, 15-23. 


\section{NOTAS}

1. Las opiniones expresadas en este artículo pertenecen a su autora y no representan una postura oficial o los puntos de vista de la Guardia Costera de los Estados Unidos o de su Comandante.

2. En dicho marco, las iniciativas para el esclarecimiento de estos delitos provinieron de ONGs y de partidos políticos, entre otros. El Frente Amplio y el Partido Nacional crearon en el Parlamento tres comisiones investigadoras para clarificar la situación de los desaparecidos (1985), el secuestro y asesinato de los representantes nacionales Zelmar Michelini y Héctor Gutiérrez Ruiz (1985) (investigación a la que haré referencia posteriormente) y la muerte de Cecilia Fontana de Heber (1986).

3. Vale la pena mencionar aquí que un importante documento había sido publicado un mes antes del referéndum, Uruguay: Nunca Más, elaborado en base a testimonios recopilados por el Servicio de Paz y Justicia (SERPAJ) y una encuesta a presos políticos realizada por Equipos Consultores Asociados. Este libro articulaba un enfoque amplio de la experiencia de la prisión, la represión y el autoritarismo pero, al quedar asociado con el referéndum para derogar la Ley de Caducidad, perdió relevancia al no prosperar el mismo (Markarian \& Marchesi, 2012: 224).

4. Los familiares de las víctimas vieron este proyecto como un avance en la consecución de «verdad y justicia», al tiempo que demandaron profundizar los esfuerzos. Los resultados de sus propias investigaciones fueron recogidos en el volumen A todos ellos, publicado en el año 2004 (Markarian \& Marchesi, 2012: 226-227).

5. Bajo su mandato, más de sesenta casos de violaciones a los derechos humanos fueron excluidos del alcance de la Ley de Caducidad, y se concretaron importantes condenas, como la del ex canciller Juan Carlos Blanco y la del ex dictador general (R) Gregorio Álvarez. Entre los casos que se pudieron reabrir e investigar, se encuentra, significativamente, el secuestro y asesinato de Michelini y Gutiérrez Ruíz (Lessa \& Fried, 2011: 37). Por otra parte, a los efectos de concretar en la práctica una de las disposiciones de la Ley de Caducidad que, a pesar de eliminar la pretensión punitiva del Estado, sí habilitaba la investigación de las desapariciones forzadas ocurridas entre 1973 y 1984, encargó esta tarea a un grupo de docentes y estudiantes universitarios liderados por tres destacados historiadores de la Universidad de la República. El resultado de esta investigación fueron cinco voluminosos tomos publicados en el año 2007, acompañados de otros tres surgidos dos años más tarde (Markarian \& Marchesi, 2012: 227-228).

6. La desaparición forzada de su nuera había sido infligida por agentes del Estado uruguayo, mientras que su nieta había sufrido supresión de su identidad y nacionalidad (Lessa \& Fried, 2011: 40).

7. Todas las traducciones son mías.

8. En este marco, el documental fue proyectado en Tacuarembó, Canelones, Rocha, Montevideo, Florida, San José, Colonia, Cerro Largo, Treinta y Tres y Salto (Efecto Cine, Calendario de Cine Nacional 2008/2009).

9. Las películas fueron exhibidas en las cinco salas que integran la Red de Salas Digitales del Mercosur, localizadas en Artigas, Castillos, Florida, Fray Bentos y Montevideo («Madres y familiares de desaparecidos organizan muestra de cine»).

10. El diputado Héctor Gutiérrez Ruíz se había trasladado a Buenos Aires junto a su esposa y sus cinco hijos con el advenimiento del golpe de Estado en Uruguay el 27 de junio de 1973. Por su parte, el senador Zelmar Michelini había llegado a la capital bonaerense el día antes de producirse el golpe para advertirle al senador Erro, del Frente Amplio, que no regresara al Uruguay ya que había perdido sus fueros. El quiebre institucional determinó que Michelini no pudiera retornar al país (Markarian, 2005: 72). 
11. De hecho, Michelini estaba invitado a declarar en el Senado de Estados Unidos, por invitación de Edward Kennedy, para hablar sobre la violación de los derechos humanos en Uruguay (De León Orpi, 2011: 186). Como señala Vania Markarian, Michelini tuvo el gran mérito de lograr convocar a todos los diferentes sectores de uruguayos exiliados en Buenos Aires (76). Por otra parte, fue el precursor de un nuevo y renovado activismo de izquierda marcado por la «narrativa humanitaria» y que, «con el objetivo principal de alcanzar a las organizaciones internacionales, los gobiernos extranjeros y los actores transnacionales, pospuso (sin sustituir) las viejas metas revolucionarias de subvertir la estructura de clase y tomar el centro del poder» (Markarian, 2005: 105).

12. Según Álvaro de Giorgi, Sanguinetti resignifica los hechos recientes (2014: 111) convirtiendo la amnistía otorgada a los presos políticos en un "perdón concedido especialmente hacia los tupamaros» (109), aún cuando estos habían sido expresamente excluidos de tal amnistía y sometidos a un proceso diferente (102-103 y 109). Esta idea está en consonancia con su afirmación acerca de que el golpe de Estado «fue el resultado de un largo proceso de deterioro institucional en el cual el factor dominante fue la aparición de una guerrilla de izquierda que hizo salir a los militares de su posición natural» (112). Del mismo modo, Sanguinetti resemantiza la «caducidad»(114), que originalmente se fundamentaba como intento de frenar una posible insurrección militar y como resultado de las negociaciones del Club Naval. En tal sentido, convierte a la misma en:

«[...] el corolario lógico de la amnistía concedida a guerrilleros -inexistente fácticamente-; y el fundamento de ambas medidas no puede ser otro que tanto unos - militares- como otros guerrilleros- tuvieron el mismo grado y nivel de responsabilidad en cuanto al terror provocado sobre una sociedad civil indefensa y no preparada para recibir tan tremendo golpe» (115).

En consecuencia, las concepciones del ex mandatario se adscriben a la teoría conocida como de «los dos demonios» que, en el caso uruguayo, no solamente da cuenta del origen del golpe de Estado sino que da sentido también al período 1968-1984, entendido como «pasado reciente» (81). En su particular versión, dos fuerzas desequilibradas e irracionales (95), los guerrilleros y los militares, se enfrentaron violentamente en el país mientras la sociedad civil en su conjunto resultó ser la víctima de sus atropellos (80). Esta concepción dialoga con/ deconstruye el discurso militar de la dictadura, según el cual, en un ambiente fuertmente polarizado, un único agresor, el «terrorismo subversivo» había cargado las tintas sobre su principal víctima, las Fuerzas Armadas (81). Pero también rivaliza con aquella contramemoria surgida de la movilización social, de acuerdo con la cual un solo demonio de color verde, los militares, habían reprimido con brutalidad al conjunto de la ciudadanía inocente (84). Esta «narrativa de la guerra» desarrollada por Sanguinetti se vio complementada también por las «narrativas de la pacificación y la reconciliación», que implicaban cubrir el pasado con un manto de olvido en aras de la construcción y consolidación del futuro del país (Lessa, 2013: 176).

\section{RESÚMENES}

En mi artículo me propongo analizar el documental D.F. (Destino Final) de Mateo Gutiérrez (Uruguay, 2008), en el que el realizador rescata la figura de su padre, Héctor Gutiérrez Ruiz, diputado y presidente de la Cámara de Representantes, asesinado en su exilio bonaerense en 1976 junto al senador Zelmar Michelini. Las declaraciones de los entrevistados, los álbumes de familia, los archivos de prensa van poblando de contenido un silencio que se eleva sobre el perfil 
fantasmático del padre perdido en la infancia, consolidándolo en su calidad y calidez humana pero también en su conformación como hombre político. Por un lado, este gesto permite explorar el límite poroso existente entre la memoria individual y familiar de un sujeto destacado de la historia uruguaya y la construcción de una narrativa de la memoria de carácter colectivo que ofrece una interpretación del pasado reciente del país. El destino de Héctor Gutiérrez Ruiz y de su núcleo familiar se erige así en alegoría de un país silenciado y violentado por doce años de dictadura cívico-militar y un preámbulo no menos ominoso. Por otro, a través de los silencios que el film opta por mantener, vinculados fundamentalmente a los procesos legales asociados a los autores intelectuales y materiales del crimen, nos brinda un acceso privilegiado al acercamiento afectivo del realizador a la necesidad de la recuperación de la memoria traumática y el esclarecimiento de la verdad en los casos de violaciones a los derechos humanos, así como también a las posibilidades y limitaciones del establecimiento de la justicia.

Dans cet article est proposée une analyse du documentaire D.F. (Destino Final) de Mateo Gutiérrez (Uruguay, 2008) dans lequel le réalisateur arrache à l'oubli la figure de son père, Héctor Gutiérrez Ruiz, député et président de la Chambre des représentants assassiné en exil à Buenos Aires en 1976 avec le sénateur Zelmar Michelini. Interviews, albums de familles et archives de presse remplissent le vide du silence qui s'élève sur le profil fantomatique d'un père perdu pendant l'enfance, en mettant l'accent sur sa qualité et sa chaleur humaine mais aussi sur sa condition d'homme politique. D'une part, ce geste permet d'explorer les limites poreuses entre mémoire individuelle et familiale d'un célèbre personnage de l'histoire uruguayenne et la construction d'une mémoire collective qui offre une interprétation du passé récent du pays. Le destin d'Héctor Gutiérrez Ruiz et de son cercle familial s'érige ainsi en allégorie d'un pays victime du silence et de la violence de douze années de dictature précédées d'un préambule non moins abominable. D'autre part, à travers les silences que le film opte pour laisser, fondamentalement par rapport aux procès associés aux auteurs intellectuels et matériels du crime, ce documentaire nous offre un accès privilégié à l'approche affective du réalisateur de la nécessité de récupération de la mémoire traumatique et de recherche de la vérité sur les cas de violations aux droits de l'homme, ainsi que sur les possibilités et les limites du processus cherchant à rendre justice.

In this article, I will analyze the documentary D.F. (Destino Final) of Mateo Gutierrez (Uruguay, 2008), in which the filmmaker rescues the figure of his father, Hector Gutierrez Ruiz, deputy and president of the House of Representatives, murdered during his exile in Buenos Aires in 1976 along with Senator Zelmar Michelini. Statements, family albums and press archives fill the silence that rises above the phantasmagorical profile of a father lost during childhood, consolidating his quality and human warmth and also his role as a political man. On the one hand, this documentary allows you to explore the existing porous boundary between individual and family memory of a subject highlighted in Uruguayan history and to build a narrative memory of a public character that offers an interpretation of the recent past of the country. The destiny of Hector Gutierrez Ruiz and his family nucleus is built as an allegory of a muted and violated by twelve years of civil-military dictatorship country with a no less ominous preface. On the other, through the silences that the film chooses to keep, fundamentally linked to the legal processes associated to the intellectual and material authors of the crime, this documentary gives us privileged access to the emotional approach of the filmmaker and expose the need for traumatic memory recovery and clarify the truth in cases of human rights violations, as well as the possibilities and limitations of the establishment of justice. 
ÍNDICE

Mots-clés: mémoire, vérité, justice, documentaire uruguayen, Mateo Gutiérrez, Héctor Gutiérrez Ruíz

Keywords: memory, truth, justice, Uruguayan documentary, Mateo Gutierrez, Hector Gutierrez Ruíz

Palabras claves: memoria, verdad, justicia, documental uruguayo, Mateo Gutiérrez, Héctor Gutiérrez Ruíz

\section{AUTOR}

\section{ELIZABETH RIVERO}

U.S. Coast Guard Academy 